\title{
Will the Combination of Public Education and Medical Innovation Improve the Outcomes of Sudden Cardiac Death?
}

\author{
Lionel Lamhaut, MD; Christian Spaulding, MD
}

\section{"Imagination is raising the level of reality" Gaston Bachelard (1884-1962)}

Sudden cardiac death $(\mathrm{SCD})$ remains a major public health problem, with overall survival rates ranging between $2 \%$ and $5 \%$. Community-based interventions have demonstrated effectiveness in increasing the number of patients who reach hospital alive. However, public awareness programs are hard to implement and their effectiveness difficult to estimate in clinical practice. Hence, many guidelines are based on consensus. The 2010 Cardiopulmonary Resuscitation (CPR) guidelines recommended that citizens previously trained in CPR provide $30: 2 \mathrm{CPR}$ and that emergency medical system (EMS) dispatchers provide telephone instruction in chest-compressiononly CPR for citizens not trained in CPR. However, there are few studies comparing both techniques. ${ }^{1}$

\section{Article p 2742}

In this issue of the Journal, Nago et al report their results of dispatcher-assisted instruction in CPR using data from the AllJapan Utstein registry. ${ }^{2}$ An impressive number of SCDs $(173,565)$ were analyzed. On arrival at the scene, EMS responders assessed the status of dispatcher-assisted CPR instruction and bystander CPR technique (chest compression with or without rescue breathing). The primary endpoint was favourable neurological outcome 30 days after cardiac arrest. Chest-compression-only $\mathrm{CPR}$ resulted in better neurological outcome than standard CPR in the whole cohort and in the subgroup of cardiac cause. These results support the use of chest-compression-only CPR for bystander witnessed out-of hospital cardiac arrest in all adults.

The authors should be congratulated on the impressive amount of data available in the registry. Furthermore, the proportion of dispatcher-assisted CPR instruction was already high at the beginning of the study and increased year by year, up to $43.9 \%$. This clearly shows that Japan is at the forefront of public awareness programs on cardiac arrest. However, despite this huge investment, 30-day neurological favourable survival was low, slightly over $4 \%$. How can we improve these results?

\section{Public Education: Young and Simple}

More than half of the bystanders hung up before dispatcher CPR instruction and one-third of the bystanders receiving dispatcher CPR instruction did not attempt bystander CPR. Bystanders are often unable or unwilling to perform CPR regardless of whether dispatcher CPR instruction is provided or not. ${ }^{3}$ The future is most certainly in public education programs provided in schools to children who are quick learners and have less apprehensive of performing CPR. ${ }^{4}$ Furthermore, chest compressiononly CPR is easier to learn and is most certainly easier to accept compared with CPR using mouth-to-mouth ventilation. Cardiologists should be involved in these programs and volunteer to teach at schools on a regular basis.

\section{Automatic External Defibrillators: Great, But Not Enough} Automatic external defibrillators (AEDs) have been available for more than 10 years. ${ }^{5}$ It is difficult to avoid seeing them when you land from a long and gruelling flight and are walking towards customs in an international airport. AEDs are an efficient method of delivering defibrillation to persons experiencing out-of-hospital cardiac arrest (OHCA) and their use by both traditional and non-traditional first-responders is safe. However, the availability of AEDs will reduce SCD mortality only if they are associated with a program of public education on CPR for SCD, which must be repeated on a regular basis. Each country or region must find the magic solution with programs organized by the government, health ministries, or non-profit organizations.

\section{Chain of Survival: Learn to Work Together}

Treatment of cardiac arrest is a chain with many "links". The majority of SCDs are presumed to be of cardiac arrest. Data on the use of coronary angioplasty is lacking in the All-Japan Utstein registry, but other registries have reported favourably on the use of immediate coronary angioplasty in survivors of OHCA. ${ }^{6,7}$ Close collaboration of prehospital EMS, interventional cardiologists and intensive care unit physicians in hospitals specializing in cardiac arrest is necessary to improve the outcome of survivors of OHCA. ${ }^{8}$ Furthermore, the same collaborators should also be actively involved in primary and sec-

The opinions expressed in this article are not necessarily those of the editors or of the Japanese Circulation Society.

Received August 3, 2013; accepted August 5, 2013; released online August 27, 2013

Centre d'expertise de la mort subite, Inserm UMR-S970, Paris Cardiovascular Research Centre, Paris Descartes University (L.L., C.S.); D.A.R. and SAMU de Paris, Hôpital Necker, Assistance Publique Hôpitaux de Paris, and Paris Descartes University (L.L.), and Cardiology Department, Hôpital Européen Georges Pompidou, Assistance Publique Hôpitaux de Paris and Paris Descartes University (C.S.), Paris, France

Mailing address: Christian Spaulding, MD, Cardiology Department, Hôpital Européen Georges Pompidou, 20 rue Leblanc, 75015 Paris,

France. E-mail: christian.spaulding@egp.aphp.fr

ISSN-1346-9843 doi:10.1253/circj.CJ-13-0995

All rights are reserved to the Japanese Circulation Society. For permissions, please e-mail: cj@j-circ.or.jp 
ondary prevention. People must be educated to call the EMS if they experience chest pain.

\section{Pushing the Limits: Refractory Cardiac Arrest}

What should be done when patients remain in refractory cardiac arrest despite multiple defibrillations? Chen et al reported on the use of extracorporeal life support (ECLS) in cases of refractory in-hospital cardiac arrest. Of 975 patients with inhospital cardiac arrest events who underwent CPR for longer than $10 \mathrm{~min}, 113$ were enrolled in the conventional CPR group and 59 in the extracorporeal CPR group. In the propensity score analysis, there was a significant difference in survival to discharge (hazard ratio [HR] $0.51,95 \%$ confidence interval [CI] 0.35-0.74, $\mathrm{P}<0.0001$ ), 30-day survival (HR 0.47, 95\% CI 0.28$0.77, \mathrm{P}=0.003$ ), and 1-year survival (HR $0.53,95 \% \mathrm{CI} 0.33$ $0.83, \mathrm{P}=0.006$ ) favouring extracorporeal $\mathrm{CPR}$ over conventional CPR. ${ }^{9}$ More recently, Lamhaut et $\mathrm{al}^{10}$ reported a pilot study on the implantation of ECMO by non-surgeons in patients with OHCA. Prehospital use of ECLS seems feasible. Larger studies are obviously necessary, but this provocative approach could be part of the jigsaw puzzle being put in place by numerous players to reduce the mortality of SCD.

The All-Japan Utstein registry is a good example of what should be done in every country waging war against the high mortality of SCD. Registries must monitor the outcome of each patient, and the data must be analyzed objectively to improve the global management of SCD. In the past 20 years, the mortality and morbidity of acute coronary syndromes have been lowered drastically by using a combination of medical therapy and interventional cardiology. One of the "New Frontiers" for innovation and imagination for the next 20 years will be to reduce the mortality of SCD. This may be achieved by a combination of public education and medical innovation. Let's all encourage the team players who are ready to embark on this difficult mission.

\section{Disclosures}

Dr Lamhaut reports receiving research grants and reimbursement for travel expenses from Maquet Holding GmbH and Co. Professor Spaulding re- ports receiving research grants on cardiac arrest from the French Ministry of Health, lecture fees and remuneration for attending meetings (Cordis Johnson and Johnson, Astra Zeneca, Servier, Medtronic) and reimbursement for travel expenses (Cordis Johnson and Johnson, Astra Zeneca, Lilly, Abbott Vascular, Medtronic).

\section{References}

1. International Liason Committee on Resuscitation. 2010 International Consensus on Cardiopulmonary Resuscitation and Emergency Cardiovascular Care Science With Treatment Recommendations Circulation 2010; 122: s-249-s-638

2. Japanese Circulation Society Resuscitation Science Study Group. Chest-compression-only bystander cardiopulmonary resuscitation in the $30: 2$ compression-to-ventilation ratio era: Nationwide observational study. Circ J 2013; 77: 2742-2750.

3. Taniguchi T, Sato K, Fujita T, Okajima M, Takamura M. Attitudes to bystander cardiopulmonary resuscitation in Japan in 2010. Circ J 2012; 76: $1130-1135$.

4. Plant N, Taylor K. How best to teach CPR to schoolchildren: A systematic review. Resuscitation 2013; 84: 415-421.

5. Marenco JP, Wang PJ, Link MS, Homoud MK, Estes NA 3rd. Improving survival from sudden cardiac arrest: The role of the automated external defibrillator. JAMA 2001; 285: 1193-1200

6. Spaulding CM, Joly LM, Rosenberg A, Monchi M, Weber SN, Dhainaut $\mathrm{JF}$, et al. Immediate coronary angiography in survivors of out-of-hospital cardiac arrest. $N$ Engl J Med 1997; 336: 1629-1633.

7. Dumas F, Cariou A, Manzo-Silberman S, Grimaldi D, Vivien B, Rosencher J, et al. Immediate percutaneous coronary intervention is associated with better survival after out-of-hospital cardiac arrest: Insights from the PROCAT (Parisian Region Out of hospital Cardiac ArresT) registry. Circ Cardiovasc Interv 2010; 3: 200-207.

8. Tagami T, Hirata K, Takeshige T, Matsui J, Takinami M, Satake M, et al. Implementation of the fifth link of the chain of survival concept for out-of-hospital cardiac arrest. Circulation 2012; 126: 589-597.

9. Chen YS, Lin JW, Yu HY, Ko WJ, Jerng JS, Chang WT, et al. Cardiopulmonary resuscitation with assisted extracorporeal life-support versus conventional cardiopulmonary resuscitation in adults with in-hospital cardiac arrest: An observational study and propensity analysis. Lancet 2008; 372: 554-561.

10. Lamhaut L, Jouffroy R, Soldan M, Phillipe P, Deluze T, Jaffry M, et al. Safety and feasibility of prehospital extra corporeal life support implementation by non-surgeons for out-of-hospital refractory cardiac arrest. Resuscitation 2013 July 1, doi:10.1016/j.resuscitation.2013.06.003 [Epub ahead of print]. 